character of which is not readily recognized. Also, the climatic records of the humid tropics differ altogether from those found in more arid latitudes, and the effect upon fauna and sediments is such as to make direct correlations with the Quaternary of the Asiatic mainland less readily available than was at first anticipated.

The new site of the Pithecanthropus skull and mandible near Sangiran, north of Solo, assures beyond doubt the Middle Pleistocene age of this fossil. Its stratigraphic location was in the lower portion of the 'Trinil beds', which are here overlain by some $150 \mathrm{ft}$. of Middle and Upper Pleistocene fossiliferous strata, all of which are clearly exposed in one section. Especially clear is the position of the infant skull of Homo modjokertensis v. Koenigswald, near Modjokerto in eastern Java. Despite the relatively shallow depth at which the skull was discovered ( $3 \mathrm{ft}$. ), it was evident that in the absence of soils and terraces, nothing could have obscured the true location and stratigraphy of this fossil. Its age, according to von Koenigswald, is Lower Pleistocene because of its association with certain mammals, such as Hippopotamus antiquus and Cervus zwaani, as appear to be ancestral to others found in the Trinil fauna.

In concluding this report, I wish to express our sincerest appreciation for the financial support which the American Philosophical Society, Harvard University and the Carnegie Institution gave to this undertaking. We also wish to thank the Director of the Geological Survey of India, and the members of the Geological Department of Burma and our colleagues in Java for the friendly co-operation extended to us.

\title{
International Committee on Social Relations of Science
}

THE Committee on Science and its Social 1 Relations (C.S.S.R.), instituted by the International Council of Scientific Unions, in May of last year, held its second meeting in Paris this year, when a number of organizational questions connected with the work undertaken were discussed. From a report prepared by the secretary the following points may be mentioned:

As stated already (Nature, 140, 983; 1937. 141,723 ; 1938), the main work of the C.S.S.R. for the present is to collect materials for the preparation of a report and of bibliographies on the social relations of science, to be presented at the next meeting of the International Council in 1940, and thereafter, it is hoped, to be printed for wide circulation. For the execution of this plan, the C.S.S.R. has applied to the national academies, or other nationally representative bodies of various countries, and to a number of international scientific organizations, with the request to assist it in its task by supplying information, and by appointing correspondents who may gather around themselves other men of science interested in the work of the C.S.S.R., so as to form local or special groups co-operating with the latter. The Royal Society of London has nominated Prof. F. E. Weiss as its correspondent, and a subcommittee, with members for physics, chemistry, engineering and, if possible, also for medicine and for some other branches of science, is being formed.

To guide correspondents in furnishing their communications to the C.S.S.R., it was proposed to draw up questionnaires, indicating the points which should be judged to come within the scope of the inquiry. The preparation of these ques- tionnaires was a kind of experiment, as in a way they should form a programme for analysing the manifold influences that science and human society exert upon each other. Various points of view presented themselves, according to which topics might be classified; on one hand, attention should be given to the influence on social relations emanating from the application of a number of definite recent scientific discoveries ; on the other, the influence of science on the outlook of men and women should be considered. The relation between certain subjects and the life of human society further could be investigated according to national points of view, or from that of the various domains of science themselves.

It was decided, therefore, in the first place to draw up a 'general questionnaire', intended as a guide for the use of correspondents of the nationally representative scientific organizations of the various countries. The subjects listed in this questionnaire have been grouped under three headings, as follows : (1) the meaning of scientific research for the development of our world picture - to be understood not only in the philosophical sense, but also in the sense of the set of ideas with which the public (in its various forms of appearance) is operating ; (2) the influence of the applications of scientific work upon human society, the transformations that are induced by them and the adaptations which are required in consequence; (3) reactions of human society upon scientific work.

In connexion with the experimental character of the work, it may very well appear that other subjects besides those listed will have to be introduced, or that various questions should be framed 
differently. It must be remarked also that, owing to the structure of the International Council, in which the medical and engineering sciences, agriculture, sociology and economics have no representation, problems referring to the latter subjects provisionally have been left aside, the more so as these subjects require a different treatment and should not be attacked before some experience and contact with the organizations specially created for them might have been obtained. Only a few 'borderland' problems have been touched upon here and there.

In asking the national correspondents to give attention to the 'general questionnaire', it is not expected that they should treat all the subjects listed in full. The extent to which information can be supplied will depend upon the measure in which attention is given to science in the various countries, and thus may largely differ from one country to another. It is possible also that certain questions may not be directly applicable to the conditions found in some countries. It has been suggested that correspondents leave aside questions which appear to them to bear no relevance to the situation in their countries, and either restrict themselves to the other questions or give information in a more independent form.

It should be emphasized, however, that the C.S.S.R. hopes to receive information concerning the many points of view which may be developing in various countries. Along with the list of questions for national correspondents, a series of questionnaires has been drawn up in which the subjects are considered from the points of view of the particular branches of science. These questionnaires are not intended for consideration by the national correspondents, but are forwarded to correspondents of international scientific organizations. In part they contain some of the same topics as had been brought together in the 'general questionnaire', but for a number of subjects more detailed problems have been noted. These questionnaires thus far have been devised for : mathematics, astronomy, mechanics, physics, chemistry, biology, geophysical sciences, geography.

The C.S.S.R. has also requested correspondents to supply a bibliography or a list concerning summarizing and reviewing or abstracting work that is being done with respect to scientific publications, either in their country (in the case of national correspondents) or in the branch of science represented by them (in the case of correspondents from scientific organizations). Such lists should give the names of progress reports, collections of abstracts of scientific literature, names of abstracting and reviewing organizations, science press service where this is present, etc.

The C.S.S.R. hopes that along with the help given by correspondents and their sub-committees, co-operation may be obtained and organized with other bodies occupied with similar problems.

At the present moment there seems to be a possibility of coming into contact with the British Association for the Advancement of Science-at the forthcoming Cambridge meeting the Council of the British Association will present a scheme for the establishment of a special Division for the social and international relations of science (see Nature, July 30, p. 195); and with the American Association for the Advancement of Science.

Attempts are being made to secure the foundation of an organization for the study of the social relations of science also in Holland. Such organizations, which should be formally wholly independent of the C.S.S.R., can perform much useful work by promoting special investigations on problems of importance for the country where they are working, for which purpose-assuming that the necessary financial means can be found-'research students', for example, might be appointed. At the same time they could assist the correspondent of the C.S.S.R. in his work of collecting information according to the general questionnaire, while, on the other hand, the C.S.S.R. can help in establishing international contacts, and in correlating results brought forward from different countries. Moreover, such organizations may find the possibility of considering sociological and economic problems, which fall outside the scope of the I.C.S.U. and the C.S.S.R.

It is expected, finally, that assistance also may be obtained from individual scientific investigators who take an interest in the work of the C.S.S.R. Apart from the help that may be asked from them with reference to particular scientific topics, there are the following points concerning which views or information often can be given better by individual persons than by official organizations :

(a) The part played by scientific thought in the outlook of various social groups.

(b) The forms in which scientific workers and their work are involved in the various struggles and conflicts of human society.

(c) The forms in which the consciousness of a social responsibility of science and of scientific workers is taking shape.

Scientific workers who desire to give information or to express views on points coming under the scope of the Committee's work, are requested to communicate with the correspondent for their country or their branch of science, or directly with the secretary of the C.S.S.R. (Prof. J. M. Burgers, van Houtenstraat 1, Delft). The secretary of the C.S.S.R. also will be glad, upon application, to forward copies of the report or of the questionnaires to persons interested. 